\title{
Article \\ Classification of Fire Damage to Boreal Forests of Siberia in 2021 Based on the dNBR Index
}

\author{
Evgenii Ponomarev ${ }^{1,2, *(D)}$, Andrey Zabrodin ${ }^{3}$ and Tatiana Ponomareva ${ }^{1,2}$ \\ 1 V.N. Sukachev Institute of Forest, Federal Research Center, Russian Academy of Science, Siberian Branch, \\ 660036 Krasnoyarsk, Russia; bashkova_t@mail.ru \\ 2 Department of Ecology and Environment, Siberian Federal University, 660041 Krasnoyarsk, Russia \\ 3 Federal Research Center "Krasnoyarsk Science Center of the Siberian Branch of the Russian Academy of \\ Sciences", 660036 Krasnoyarsk, Russia; azabrodin@ksc.krasn.ru \\ * Correspondence: evg@ksc.krasn.ru; Tel.: +7-3912494092
}

Citation: Ponomarev, E.; Zabrodin, A.; Ponomareva, T. Classification of Fire Damage to Boreal Forests of Siberia in 2021 Based on the dNBR Index. Fire 2022, 5, 19. https://doi.org/10.3390/ fire5010019

Academic Editor:

Palaiologos Palaiologou

Received: 28 December 2021

Accepted: 26 January 2022

Published: 29 January 2022

Publisher's Note: MDPI stays neutral with regard to jurisdictional claims in published maps and institutional affiliations.

Copyright: (c) 2022 by the authors. Licensee MDPI, Basel, Switzerland. This article is an open access article distributed under the terms and conditions of the Creative Commons Attribution (CC BY) license (https:// creativecommons.org/licenses/by/ $4.0 /)$.

\begin{abstract}
Wildfire in Siberia is extensive, affecting up to 15 Mha annually. The proportion of the vegetation affected by severe fires is yet unknown, and it is a problem that requires a solution because post-fire mortality of tree stands in Siberian taiga has a strong effect on the global budget of carbon. The impact of fire in our area of interest in eastern Siberia was analyzed using the normalized burn ratio (NBR) and its pre- versus post-fire difference (dNBR) applied to Landsat-8 (OLI) collected in 2020-2021. In this paper, we present the classification of fire impact in relation to dominant tree stands and vegetation types in boreal forests of eastern Siberia. The dNBR of post-fire plots ranged widely (0.30-0.60) in homogeneous larch (Larix sibirica, L. gmelinii) forests, pine (Pinus sylvestris) forests, dark coniferous stands (Pinus sibirica, Abies sibirica, Picea obovata), sparse larch stands, and Siberian dwarf pine (Pinus pumila) stands. We quantified the proportions of low, moderate, and high fire severity $(37 \%, 39 \%$, and $24 \%$ of the total area burned, respectively) in dense tree stands, which were varied to $30 \%, 57 \%$, and $13 \%$, respectively, for sparse stands and tundra vegetation dominated in the north of eastern Siberia. The proportion of severe fires varied according to the transition from dominant larch stands (33.2\% of the area burned) to pine (12.6\%) and dark coniferous (up to $26.4 \%$ ). The current proportion of stand-replacement fires in eastern Siberia is $12-33 \%$, depending on vegetation type and tree density, which is about 2500 thousand hectares in 2021 in the region. According to our findings, the "healthy/unburned vegetation" class was quantified as well at least 700 thousand hectares in 2021.
\end{abstract}

Keywords: boreal forest; wildfires; dominant tree species; normalized burn ratio; fire impact classification; fire severity; stand-replacement fires

\section{Introduction}

Wildfires in Siberia make up a significant part of the statistics of annual damage to vegetation in the world [1-3]. As materials of recent years show, areas of fires tend to rise in many regions of the world. Positive dynamics of this indicator were also noted in the forests of Siberia over the past 25 years of observations [4-6]. The fire season in 2021 was extreme and showed one of the highest levels of forest burning for the last 25 years of satellite observations [7]. Climate change will affect the occurrence of forest fires in northern regions. Today, this issue is discussed considerably for boreal forest zone [3,6]. In this direction, future fire impact on boreal forests of Siberia is a very important issue as well. Nowadays, systems of satellite monitoring (according to TERRA and AQUA/MODIS, Landsat, Sentinel data) provide instrumental control of burned areas with the declared level of accuracy.

Satellite data are important for determining the degree of forest disturbance $[8,9]$, for calculating direct fire emissions [10], monitoring the post-fire state of soils [11,12], and vegetation cover and their restoration $[13,14]$. 
Of particular interest is the problem of identifying post-fire mortality and restoration of tree stands. Satellite resources can be used to estimate the share of stand-replacement fires $[9,15]$. According to estimates of Krylov et al., up to one-third of the annual areas of fires in Siberia are accompanied by the subsequent complete loss of the stand and long-term post-fire successions [16]. Such estimates summarize remote sensing data on wildfires and the post-fire state of disturbed areas [16,17].

A number of invariant indices based on remote sensing data in the multispectral range are applied to identify the post-fire state of vegetation. Since most of the vegetation indices are ratios, these indices are invariant to the difference in illumination conditions, slope, seasons, etc.

The most well-known and widely used method for remotely assessing the state and disturbance of vegetation cover is the vegetation (chlorophyll) index, which was proposed back in 1973 [18], referred to as the normalized difference vegetation index (NDVI). Values characteristic of a healthy or depressed state were determined for various types of vegetation cover, and a significant decrease in NDVI relative to the norm after fire impact was shown already in the earliest papers on the topic [19]. A number of improved vegetation indices calculated from satellite imagery data have similar characteristics and sensitivity to the state of vegetation, such as the enhanced vegetation index (EVI), infrared percentage vegetation index (IPVI), differential vegetation index (DVI), etc.

There is also a method for detecting the stage of restoration of vegetation cover in areas after natural, anthropogenic, or human-made impacts by analyzing temperature anomalies of the underlying surface based on satellite imagery in the thermal IR spectral range $[12,20]$.

It is possible to efficiently analyze the degree of post-fire disturbance using multispectral indices calculated by taking a ratio between the difference of reflectance from the near-infrared (NIR) and the short-wave infrared (SWIR) bands, and the sum of reflectance from NIR and SWIR bands. In particular, the normalized burn ratio (NBR) index and its pre- versus post-fire difference (dNBR) are actively used for these purposes [15,21-23]. This approach to assessing the degree of fire impact on vegetation was used in [24] for fires in Canada, by Delcourt et al. [17], to analyze variations in the intensity of wildfires in Siberia, as well as in the paper by dos Santos et al. (2020) [14], to analyze post-fire damage in tropical forests. An analog of this index (short-wave $(1.6 \mu \mathrm{m})$ vegetation index (SWVI) and relative difference short-wave vegetation index (RdSWVI)) correlated with ground-based data on post-fire defoliation and dechromation of main tree stands of Siberia [25]. All studies results show high correlation $\left(\mathrm{R}^{2}=0.5-0.9\right)$ between the dNBR (RdSWVI) indices and ground survey data on vegetation damage $[14,17,24,25]$.

In this study, we used mostly the same technique. The fire impact was analyzed using the NBR and the dNBR. The threshold technique applied to the dNBR [14,21] allows the classification of fire impact on vegetation in areas burned using geospatial statistics procedure, which is a standard procedure of GIS software. The spatial accuracy of this approach is determined by the resolution of satellite data (30 $\mathrm{m}$ for Landsat/OLI). However, for fire areas typical for Siberia, this accuracy is sufficient. More accurate approaches for image classification are also available in [26,27]. However, it seems to be inapplicable for studying the current issue, both due to the lack of high-resolution remote sensing data on the territory of interest and due to the limited accuracy of the available data on fire polygons $(1000 \mathrm{~m})$ [28] and vegetation maps $(250-500 \mathrm{~m})$ [8,29].

Fire impact and proportion of severe fires in Siberia are currently presented only in a few publications $[15,16,30]$. One of the most important results is the proportion of tree mortality after fire impact. Current estimates suggest that up to $30 \%$ of burned forests of the region are killed by high-severity fire [16], which, however, does not take into account the variability associated with the resistance of certain forest-forming species to fires such as pine (Pinus sylvestris) $[4,31,32]$. Hence, the classification of fire impact needs to be quantified in relation to dominant tree stands and combinations of vegetation cover in boreal forests of eastern Siberia [8,29]. 
In this research, we discuss results on the classification of burned areas in 2021 in terms of low, moderate, and high degrees of fire impact on vegetation in relation to the dominant forest stands, close tree stands, and sparse stands and tundra of eastern Siberia. We quantified the following issues for conditions of eastern Siberia: (a) the proportion of the different degrees of fire impact on the various vegetation types, (b) areas of the class of "healthy/unburned vegetation" within remotely detected fire scars, and (c) "standreplacement fires" areas for different vegetation types, close tree stands, sparse stands, and tundra of eastern Siberia. Further study of this issue is necessary for predictive modeling of the fire impact on forests under climate change [33] and forest fire regimes increasing at the subregional level [2-4,6].

\section{Materials and Methods}

\subsection{Area of Interest}

This research was carried out for the territory of eastern Siberia within the boundaries of the Lena River Basin $\left(57-67^{\circ} \mathrm{N}, 110-135^{\circ} \mathrm{E}\right)$ (Figure 1). The total study area was $\sim 200$ million hectares, which is up to $35 \%$ of the area of total forests in Siberia.

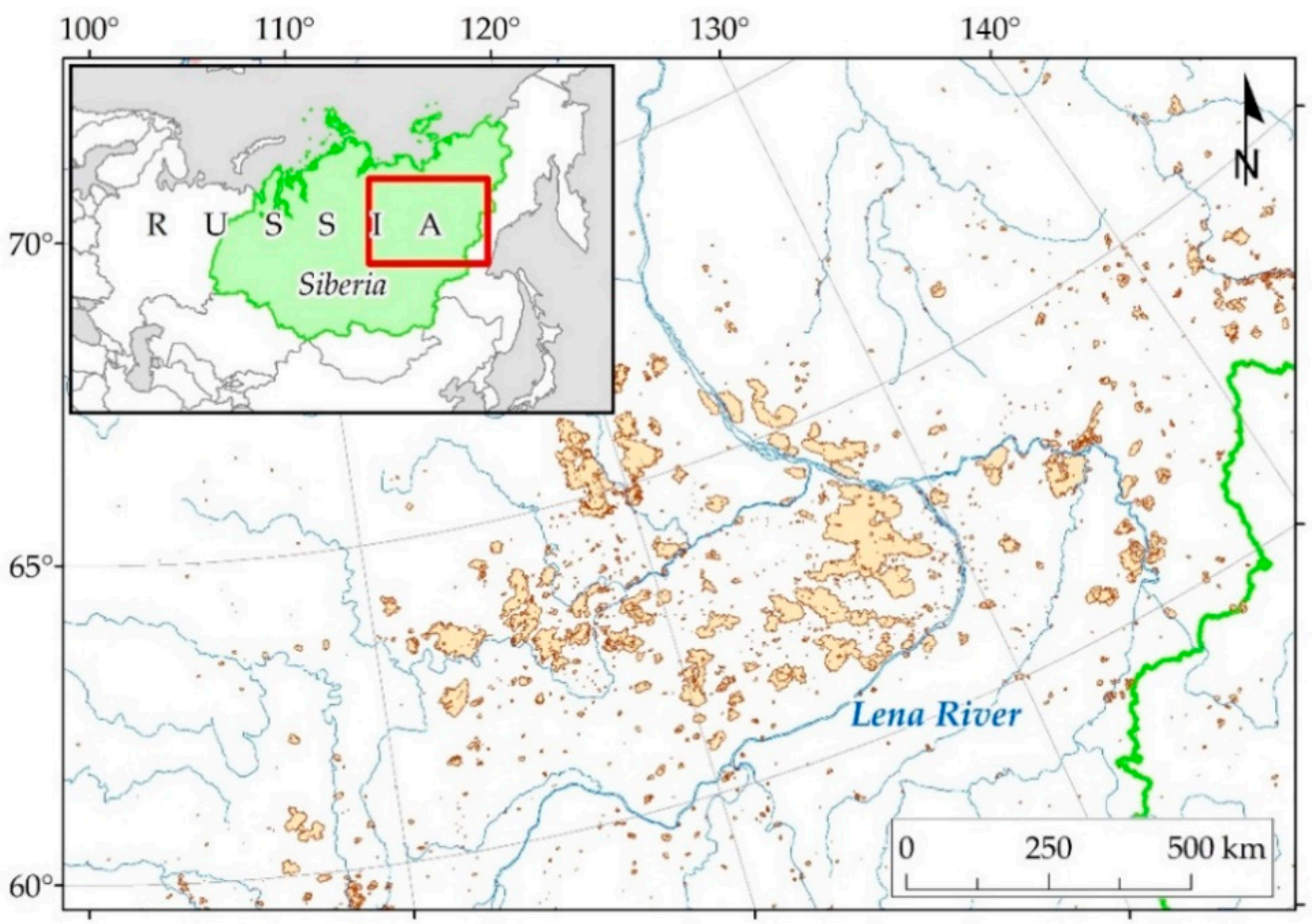

Figure 1. Fire polygons (light brown) in the Lena River Basin study area (eastern Siberia), derived from MODIS data (Terra and Aqua satellites) captured in 2021.

The main species forming stands on this territory are larch (Larix sibirica, L. gmelinii) and pine (Pinus sylvestris). These species are predominant in Siberia, accounting for up to $75 \%$ of all forests. Up to $55 \%$ is accounted for by larch and larch woodlands and up to $18 \%$ are forests with a predominance of pine stands. The remaining forest-forming species (Pinus sibirica, Abies sibirica, Picea obovata, Betula spp., Populus tremula) make up $\sim 25-27 \%$ of the study area [4]. The study area experiences the highest concentration of fires in Siberia [4,34]. Long-term statistics show that wildfires in the larch and pine forests of Siberia account for up to $77 \%$ of all fire areas $[4,10]$, while the proportion of fires in larch forests exceeds $60 \%$ of the total area damaged annually. With climate change, it is possible that fires will increase in the north of the region [3,35]. This requires the consideration of a separate class of wildfires in areas with a predominance of tundra vegetation, as well as in elevated relief elements, where Siberian dwarf pine (Pinus pumila) dominates. 


\subsection{Initial Data}

Long-term chronologies of wildfires (1996-2021) and dating of post-fire sites in 2021 for the area of interest were provided by the satellite monitoring of wildfires and GIS databank on wildfire events of the V. N. Sukachev Institute of Forest SB RAS, Federal Research Center KSC SB RAS (Krasnoyarsk, Russia) [28]. In total, more than 2000 wildfires were recorded in the region in 2021, with a total area of $>10$ million hectares according to satellite monitoring data. These data are consistent with the official statistics of the Remote Monitoring Information System of the Federal Forestry Agency of Russia for the Republic of Yakutia (eastern Siberia) (https:/ / public.aviales.ru/main_pages/public.shtml, accessed on 1 December 2021) [7].

The dates of wildfires, the coordinate reference, and the size ranges of fires were acquired from the database records. The vegetation map information was acquired using the vegetation layer of the "Vega" service of the Space Research Institute of the Russian Academy of Sciences (IKI RAS, Moscow, http://pro-vega.ru/maps/, accessed on 1 December 2021) [8,29]. From the fire database, we requested a selection of fire polygons in various vegetation classes-namely, "larch forests" and "larch woodlands" (Larix sibirica, L. gmelinii), "pine forests" (Pinus sylvestris), "Siberian dwarf pine" (Pinus pumila), "dark coniferous" (Pinus sibirica, Abies sibirica, Picea obovata), and "tundra". We took into account a unique feature of wildfires in Siberia, which is wide ranges of the size of areas burned (S)namely, (1) large-scale fires ( $>20$ thousand hectares); (2) medium-size fires (2 thousand hectares $<\mathrm{S}<20$ thousand hectares); (3) small-size fires ( $<2$ thousand hectares). We also considered differences in the effect of fire on vegetation for three categories of fires, taking into account their areas.

The initial sample of fires contained 40 events $(2 \%$ of the total number of fires in 2021 in the region), including 8 large-scale fires, 18 fires of the medium-size category, and 14 small-size fires. The total area burned in the selection was $>1.8$ million hectares, which is $10-18 \%$ of the annual area burned in 2021 in the region. Thus, the sample can be considered representative.

The satellite survey was selected from open data of the United States Geological Survey (USGS) database (https: / / earthexplorer.usgs.gov/, accessed on 1 December 2021). In total, we used 20 images of the Landsat- 8 satellite, equipped with Operational Land Imager (OLI)/Thermal Infrared Sensor (TIRS). For calculations, we used band \#5 (NIR, $\lambda=0.85-0.89 \mu \mathrm{m})$ and band \#7 $\left(\mathrm{SWIR}_{2}, \lambda=2.11-2.29 \mu \mathrm{m}\right)$ data with a spatial resolution of $30 \mathrm{~m}$ (Table 1).

Table 1. The original sample of the Landsat-8/OLI survey, which covered all selected fire polygons.

\begin{tabular}{cccc}
\hline Path & $\begin{array}{c}\text { Address of the Image } \\
\text { Row }\end{array}$ & Pre-Fire Image Date & Post-Fire Image Date \\
\hline 116 & $15,18,19$ & $01 / 09 / 2019,17 / 07 / 2020,19 / 09 / 2020$ & $06 / 09 / 2021$ \\
117 & 17 & $22 / 07 / 2019$ & $13 / 09 / 2021$ \\
119 & 18 & $22 / 07 / 2020$ & $10 / 08 / 2021,11 / 09 / 2021$ \\
121 & 16,17 & $17 / 05 / 2020,21 / 08 / 2020,05 / 06 / 2021$ & $09 / 09 / 2021$ \\
126 & $14,17,18$ & $21 / 07 / 2019,24 / 08 / 2020,09 / 09 / 2020$ & $12 / 09 / 2021$ \\
128 & 13,18 & $17 / 06 / 2019,22 / 06 / 2021$ & $26 / 09 / 2021$ \\
130 & 15,16 & $20 / 08 / 2020$ & $23 / 08 / 2021$ \\
133 & 16 & $21 / 05 / 2020$ & $28 / 08 / 2021$ \\
134 & 16 & $13 / 08 / 2013$ & $16 / 08 / 2014,08 / 06 / 2018$ \\
135 & 17,18 & $23 / 08 / 2020$ & $25 / 07 / 2021,26 / 08 / 2021$ \\
137 & 17 & $05 / 08 / 2014$ & $11 / 09 / 2016,16 / 06 / 2019$ \\
\hline
\end{tabular}

\subsection{Method}

We calculated the NBR/dNBR for each wildfire of the sampling, using the GIS package Quantum GIS (Quantum Geographic Information System, version 3.16.3, https: / / www. qgis.org / , accessed on 1 December 2021) and the semi-automatic classification plugin. First, 
conversion and pixel-by-pixel calibration were performed to convert the brightness of pixels into reflection coefficients (spectral albedo) and brightness temperature. Second, we used vector fire polygons (Figure 1) from the sample to crop the images and only process them inside the burnt area polygons. Finally, the NBR and $d N B R$ were calculated as follows:

$$
\begin{gathered}
N B R=\frac{\left(N I R-S W I R_{2}\right)}{\left(N I R+S W I R_{2}\right)}, \text { and } \\
d N B R=N B R_{\text {Prefire }}-N B R_{\text {Postfire }}
\end{gathered}
$$

where NIR is the calibrated data from the near-infrared band of $\lambda=0.85-0.89 \mu \mathrm{m}, S_{W} R_{2}$ is the data from the short-wave infrared band of $\lambda=2.11-2.29 \mu \mathrm{m}$, and $N B R_{\text {Prefire }}$ and $N B R_{\text {Postfire }}$ are pixel-by-pixel index values for the same fire scar calculated on pre- and post-fire Landsat/OLI images.

Next, we applied the threshold technique to the dNBR data $[14,21]$ to classify fire impact to vegetation in areas burned using geospatial statistics calculating procedure of Quantum GIS/ArcGIS. We obtained classification data within the boundaries of every wildfire polygon of the sampling to evaluate fire severity and degree of fire impact according to thresholds of dNBR (Table 2).

Table 2. Thresholds of the dNBR to classify fire severity and level of fire impact on vegetation cover according to $[14,21]$.

\begin{tabular}{cccc}
\hline $\begin{array}{c}\text { Degree of Fire } \\
\text { Impact }\end{array}$ & Class Number & dNBR Range & Fire Severity \\
\hline Low & 1 & $<-0.100$ & Healthy \\
& 2 & $-0.101 \ldots 0.099$ & $\begin{array}{c}\text { Nonburned } \\
\text { vegetation } \\
\text { Low severity } \\
\text { Moderate }\end{array}$ \\
& 4 & $0.100 \ldots 0.269$ & $\begin{array}{c}\text { Moderate-low } \\
\text { severity } \\
\text { Moderate-high } \\
\text { severity }\end{array}$ \\
High & 5 & $0.270 \ldots 0.439$ & High severity \\
\hline
\end{tabular}

By means of Quantum GIS/ArcGIS, we evaluated geostatistics for each class of fire severity and degree of fire impact $\left(S_{i}\right)$ as the total number of pixels (count) of each class $(i)$, taking into account the spatial resolution of the image $(30 \times 30 \mathrm{~m})$ :

$$
\left.S_{i}=\left(\text { count }_{i} \times 30 \times 30\right)\right) / 1000,000,
$$

where count is the number of pixels for a class $(i)$, and 30 is the pixel size of the Landsat8/OLI image (m).

We summarized geostatistics for three main classes of low, moderate, and high degrees of fire impact, and the class of "healthy/unburned vegetation" was evaluated separately. The highest level of fire severity we analyzed further as data on the "stand-replacement fires" class. We used generalized data on the degree of fire impact to vegetation as low fire impact (combines three ranges of dNBR values), medium fire impact (combines two ranges of dNBR values), and high fire impact (corresponding to the maxima of dNBR), as listed in Table 2. Further, we used the standard procedure of intersection in GIS to joint analysis of the classification results and vector map of vegetation cover [8,29].

\section{Results}

In total, we preprocessed and classified 40 wildfire events of different categories, as shown in Figure 2. Results were summarized, in relation to dominant tree stands and types of vegetation, based on different categories of fire events (Table 3). 

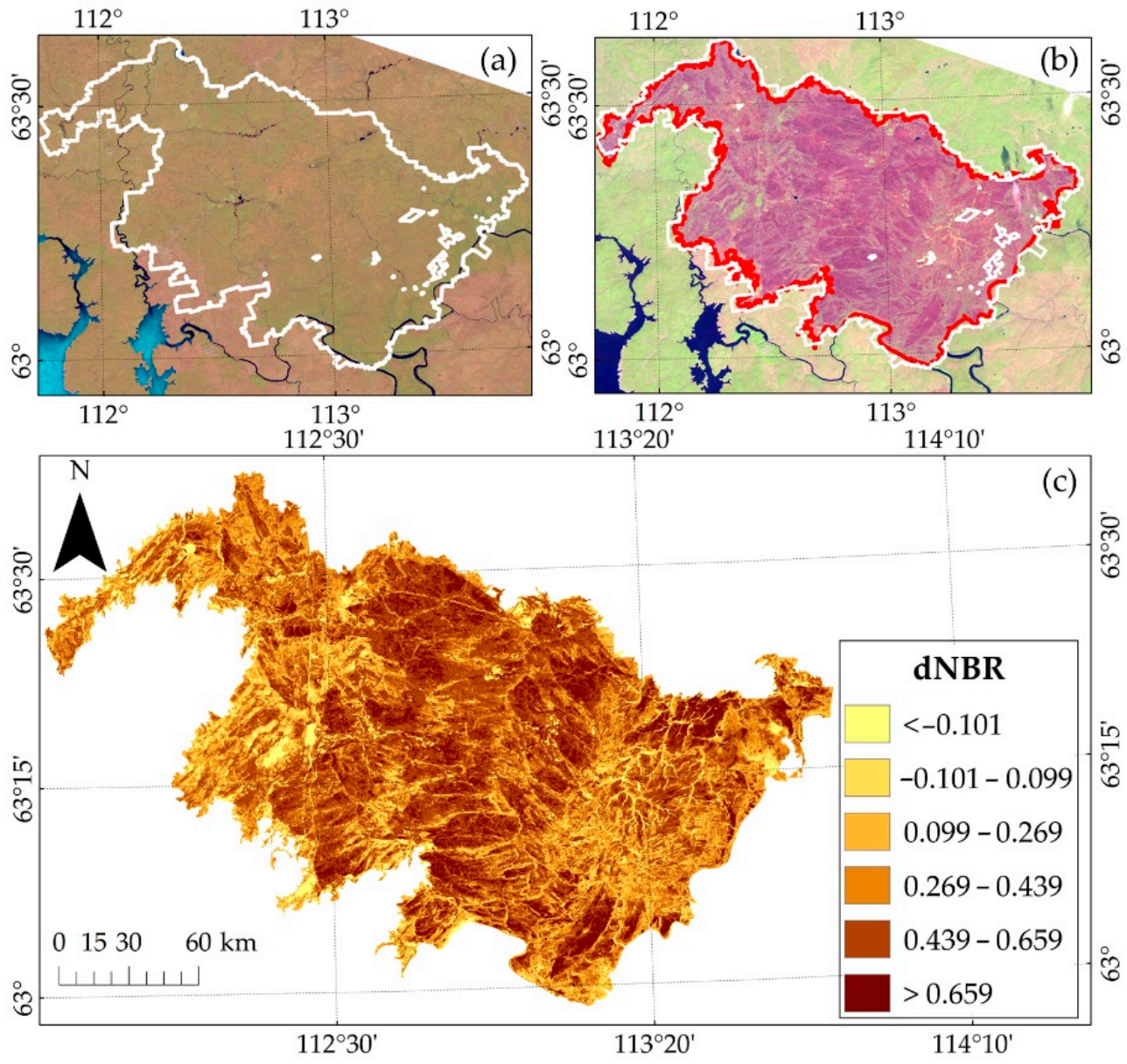

Figure 2. An example of pre-processing Landsat-8/OLI survey data for the pre-fire polygon in 2020 (a) and the post-fire polygon in 2021 (b). The classification of the fire scar in terms of dNBR ranges (c). The shape of the fire scar is shown both based on satellite detecting data (colored in white) and according to the result of classification (colored in red).

Table 3. The initial sample of fire events by dominant tree stands/vegetation types. Fire events have been categorized in terms of area burned (S).

\begin{tabular}{|c|c|c|c|c|}
\hline \multirow{2}{*}{ Dominant Tree Stands/Vegetation Types } & \multicolumn{4}{|c|}{ Fire Events of the Sampling } \\
\hline & $\mathrm{S}<2 \times 10^{3}$ ha & $2 \times 10^{3}$ ha $<$ S $<2 \times 10^{4}$ ha & $\mathrm{S}>2 \times 10^{4} \mathrm{ha}$ & Total \\
\hline $\begin{array}{l}\text { Larch (Larix sibirica, L. dahurica) } \\
\text { and Larch sparse }\end{array}$ & 3 & 5 & 4 & 12 \\
\hline Larch and Scots pine (Pinus sylvestris) * & 6 & 7 & 3 & 16 \\
\hline Scots pine (Pinus sylvestris) & 1 & 2 & 1 & 4 \\
\hline $\begin{array}{l}\text { Interface between taiga and tundra, } \\
\text { Siberian dwarf pine (Pinus pumila) }\end{array}$ & 3 & - & - & 3 \\
\hline $\begin{array}{c}\text { Dark coniferous stands (Pinus sibirica, } \\
\text { Abies sibirica, Picea obovata) }\end{array}$ & - & 3 & - & 3 \\
\hline Nonforest types/Tundra & 1 & 1 & - & 2 \\
\hline
\end{tabular}

* The proportion of larch in the stand decreases from $95 \%$ to $5 \%$, while the proportion of pine increases from $5 \%$ to $95 \%$, respectively.

The dNBR of post-fire plots ranged widely $(0.30-0.60)$ in homogeneous larch (Larix sibirica, L. gmelinii) forests ( $0.60 \pm 0.26)$, pine (Pinus sylvestris) forests $(0.30 \pm 0.22)$, dark coniferous stands (Pinus sibirica, Abies sibirica, Picea obovata) $(0.42 \pm 0.25)$, and sparse larch and Siberian dwarf pine (Pinus pumila) stands $(0.41 \pm 0.24)$. 
After threshold classifying of dNBR (Table 2) the proportions were evaluated for low, moderate, and high fire severity in dense tree stands $(37 \%, 38 \%$, and $24 \%$, of the total areas burned, respectively) and in sparse stands and tundra vegetation dominated in the north of eastern Siberia (30\%, 57\%, and $12.5 \%$, respectively). High-severity fires on average affect up to $\sim 24.1 \%$ of burned forests under the condition of close tree stands, although severe fire proportion decreases almost two times (12.5\% of the area burned on average) in sparse vegetation and tundra (Table 4 ). The degree of fire impact varied significantly, depending on the density of forest stands and the dominant tree species (Figure 3).

Table 4. The proportion (\%) of fire burned (mean, and standard deviation), characterized with low, moderate, and high degree of fire impact on vegetation in comparison both for dense forest stands and for sparse and tundra.

\begin{tabular}{ccccc}
\hline \multirow{2}{*}{ Degree of Fire Impact } & \multicolumn{2}{c}{ In Dense Forest Stands } & \multicolumn{2}{c}{ In Sparse and Tundra } \\
& Mean & SD & Mean & SD \\
\hline Low & 37.16 & 17.28 & 30.42 & 7.26 \\
Moderate & 38.79 & 6.96 & 57.09 & 7.41 \\
High & 24.05 & 11.92 & 12.49 & 7.05 \\
\hline
\end{tabular}
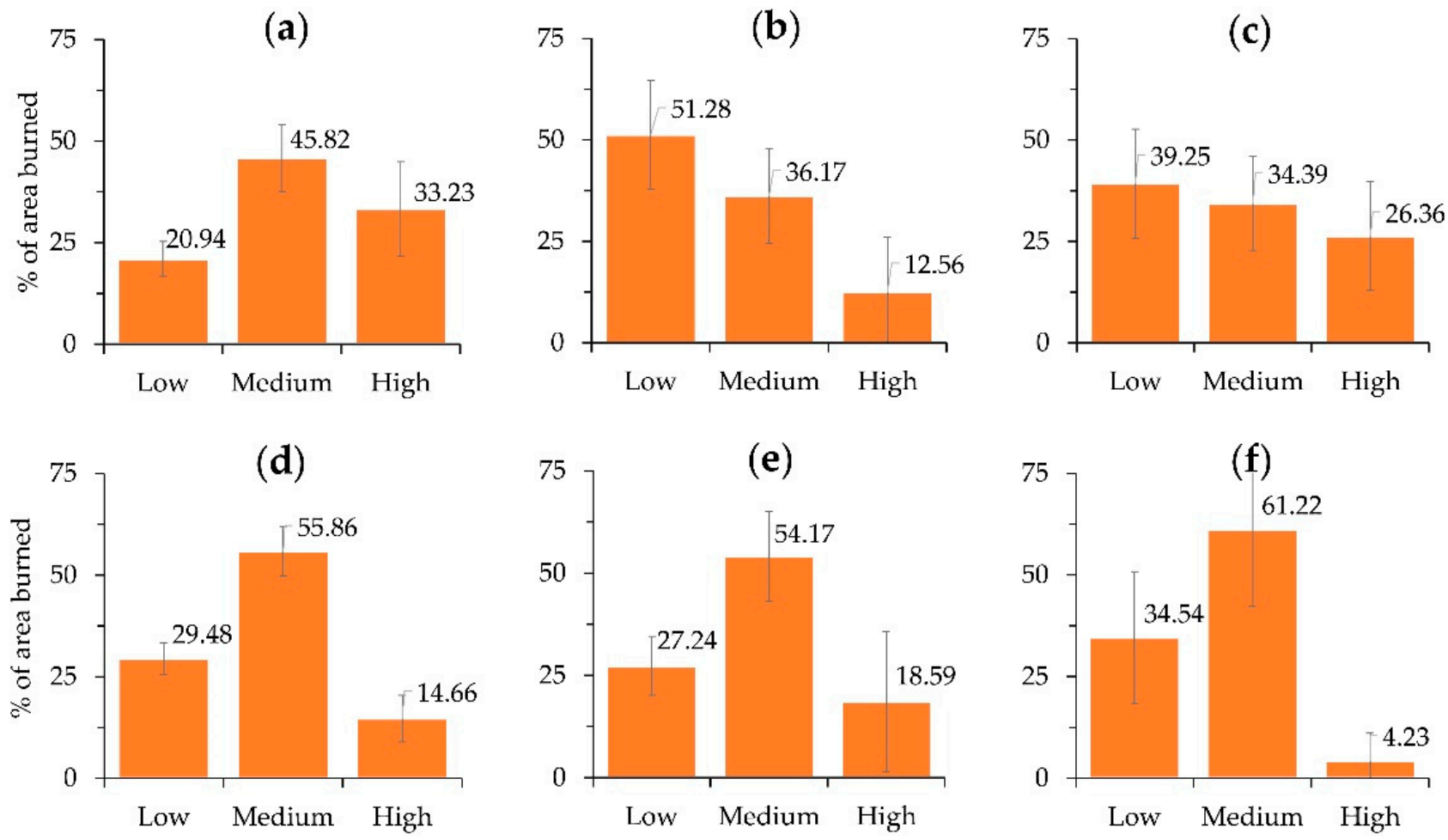

Figure 3. Severity / fire impacts (low, moderate, high) depending on dominant tree stands and types of vegetation: (a) larch close stands, (b) pine stands, (c) dark coniferous stands, (e) larch sparse, (d) Siberian dwarf pine (Pinus pumila), and (f) tundra vegetation.

The proportion of severe fires varied according to the transition from dominant larch stands $(33.2 \%$ of the area burned) to pine stands $(12.6 \%)$ and dark coniferous stands (up to $26.4 \%$ ) on average (Figure $3 \mathrm{a}-\mathrm{c}$ ). The proportion of severe fires was 2.0-2.5 times lower under conditions of vegetation types, dominated in the north $(65+\mathrm{N})$ of boreal forests of Siberia $(18.6 \%, 14.7 \%$, and $4.2 \%$, in Pinus pumila, larch sparse, and tundra, respectively) (Figure 3d-f). On average, stand-replacement fires (in terms of the highest dNBR) varied from $7-12 \%$ for the category of small-size fire to $15-20 \%$ for large-scale fire. At the same time, medium-size fire ( 2 thousand hectares $<S<20$ thousand hectares) was accompanied by the highest degree of fire damage in $25-35 \%$ of the total area burned. Hence, the 
total area of stand-replacement fires was estimated at 2500 thousand hectares in 2021 in eastern Siberia, while the total area burned was $\sim 10 \mathrm{mln}$ hectares in the region (https: / / public.aviales.ru/main_pages/public.shtml/, accessed on 1 December 2021) [7].

For all considered variants, the class of "healthy/unburned vegetation" (Table 2) was evaluated. On average, this class accounted for $5-7 \%$ of the area burned, with sporadic maxima of $12 \%$. In Table 4 , data on this class are included in the category of low degree of disturbance. However, this class should be taken into account in the future, because "healthy/unburned vegetation" accounted for about 700 thousand hectares in 2021.

Additionally, we identified a unique data series, reflecting the dNBR variety in mixed larch-pine stands (Figure 4). The dNBR changed significantly when the dominance of larch decreased from $95 \%$ to $5 \%$, whereas the dominance of pine increased from $5 \%$ to $95 \%$, respectively (Table 3). In this case, the proportion of low, medium, and high degrees of fire impact was $46.2 \%, 39.8 \%$, and $14.1 \%$, respectively, which differs from the distribution for quasi-homogeneous stands (Figures $3 \mathrm{a}, \mathrm{b}$ and 4 ).
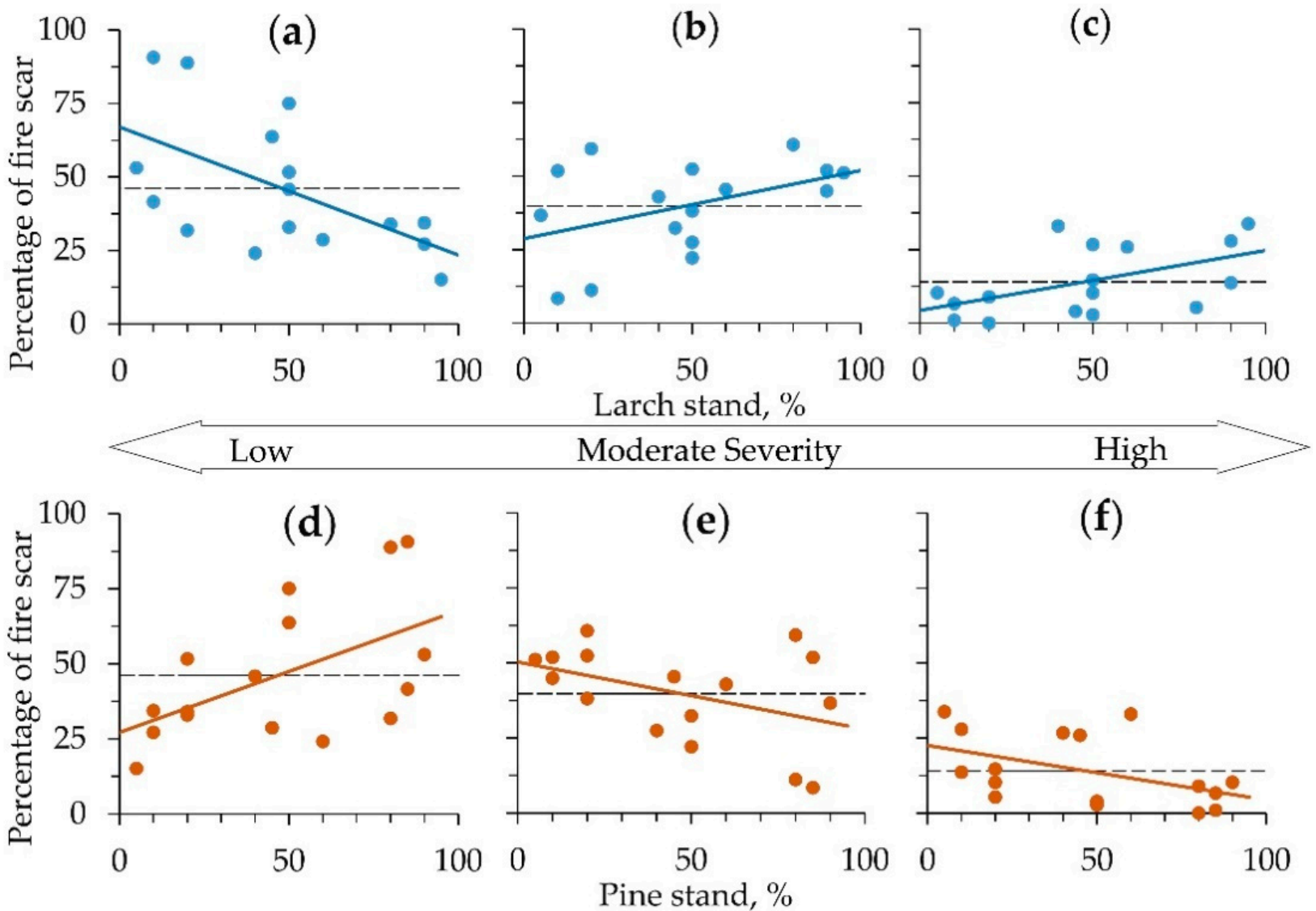

Figure 4. The dNBR for a sample of fire events in mixed larch-pine stands, where the percentage of larch dominance decreased from $95 \%$ to $5 \%(\mathbf{a}-\mathbf{c})$, while the proportion of pine increased from $5 \%$ to $95 \%(\mathbf{d}-\mathbf{f})$, respectively. The dashed line indicates the average values of low $(\mathbf{a}, \mathbf{d})$, moderate $(\mathbf{b}, \mathbf{e})$, and high $(\mathbf{c}, \mathbf{f})$ fires severity.

\section{Discussion}

Nowadays, the NBR/dNBR-based approach is well known among researchers. This type of analysis has been carried out many times previously, and its high efficiency in the analysis of the post-fire state of vegetation is discussed widely in papers of different authors. The high correlation of the index with the state of vegetation evaluated in the field measurements has been confirmed numerous times $[14,17,24,25,30]$. In our opinion, this fact is quite well substantiated in relation to the fire impact on the forests of Siberia as well $[15,17,25]$. In this sense, we did not aim to test or to validate the approach used, 
relying on the results of previous researchers of this issue for Siberia. The main result that was revealed in our research is the assessment of the fire severity and the proportion of fire severity for each of the dominant forest stands and various vegetation types in the study region. Thus, we classified data on wildfires in eastern Siberia in terms of dNBR to evaluate fire severity and degree of fire impact on vegetation, which was applied to burned areas in 2021. The dNBR ranged widely (0.30-0.60) in fire scars in homogeneous larch (Larix sibirica, L. gmelinii) forests, pine (Pinus sylvestris) forests, dark coniferous stands (Pinus sibirica, Abies sibirica, Picea obovata), and sparse larch and Siberian dwarf pine (Pinus pumila) stands.

Applying the dNBR threshold [14,21] for the highest-severity fires (Table 2), we have clarified the proportion of stand-replacement fires in the region, which is a very important characteristic of current and future fire regimes. Available estimate $[9,16]$ suggests that up to $30 \%$ of burned forests of the region are killed by high-severity fire annually. However, the previously published estimate does not take into account the variability associated with the resistance/vulnerability of certain forest-forming species [4,31,32] to fires in Siberian boreal forests. We quantified the proportion of severe fires, which varied according to the transition from dominant larch stands $(33.2 \%$ of the area burned) to pine $(12.6 \%)$ and dark coniferous (up to $26.4 \%$ ) on average (Figure 3a-c). These founds improved estimates on the proportion of stand-replacement fires in eastern Siberia under the current fire regime. The severe fires were estimated as $12.6 \%$ in Pine (Pinus sylvestris) forests of Siberia, which is similar to previous studies of crown fires/stand replacement fires (from $6.5 \%$ up to $17.5 \%$ ) [36,37] in the region. Krylov et al. declare that up to one-third of the annual areas of fires in Siberia are accompanied by the subsequent complete loss of the stand [16], which is similar to our assessment obtained for conditions of larch close stands.

According to available maps of vegetation in Siberia $[8,16,29]$, the percentage of tree cover is estimated at $<30 \%$ for sparse vegetation class and $\mathrm{f} 31-100 \%$ for close tree stands. Under these conditions, the severe/crown fire areas were estimated by bioclimatic zones of Siberia as follows: $\sim 2-7 \%$ in coniferous/larch forest of tundra, northern and sparse taiga, up to $8-19 \%$ in central Siberia taiga, and $13-25 \%$ in southern taiga [38-41]. We found that, on average, high-severity fires affect up to $\sim 24.1 \%$ of burned forests, under the condition of close tree stands, and decrease almost two times (12.5\%) in sparse vegetation and tundra (Table 4). In total, the proportions of low, moderate, and high fire severity were $37.16 \pm 17.28 \%, 38.79 \pm 6.96 \%$, and $24.05 \pm 11.92 \%$, respectively, in dense tree stands, and varied to $30.24 \pm 7.26 \%, 57.09 \pm 7.41 \%$, and $12.49 \pm 7.05 \%$, respectively, in sparse stands and tundra vegetation dominated in the north of eastern Siberia. In addition, the dNBR changed significantly in mixed larch-pine tree stands. In this case, the proportion of low, medium, and high degrees of fire impact was $46.2 \%, 39.8 \%$, and $14.1 \%$, respectively, which differs from the distribution for quasi-homogeneous stands.

Wildfire in the northern zone could be a new reality in the nearest future; thus, we could forecast that the current estimate on severe fire in the northern part of Siberia will increase under conditions of climate change [3,4,35]. It should also be taken into account that fires in the northern part of Siberia, as a rule, are very large-scale events $[4,28,34]$. Therefore, even a low percentage of severe fires means thousands and tens of thousands of hectares for each fire event in Siberia.

Tree stands experience complex fire impacts, including damaged roots (the surface root system is relevant for both pine and larch boreal forests of Siberia), damaged sapconducting pathways of trees (depending on the bark features of a tree), and thermal burn of the crown by convective heat flows (from the crown or steady, high-intensity fires) $[4,13,31,32]$. Our findings are consistent with the fact that tree stand mortality is determined both by the crown fire impact and by intense surface fires when the litter burns out, and the surface root system of trees is disturbed significantly [4,32]. The resistance of pine and larch trees to burn effects is associated with the biological features of these species [42]. Thus, the vulnerability of stands to fires is determined by the typical depth of the root in the soil for different forests [43]. It is the combination of these factors that determines the proportion of "stand-replacement fires". Therefore, taking into account 
the characteristics of various tree stands and vegetation is the most important issue of an adequate evaluation of the fire impact degree.

Another unique feature of wildfires in Siberia is the wide range of burned areas. Table 3 shows wildfires considered with reference to three categories of burned area (S): (1) large-scale fires ( $>20$ thousand hectares); (2) medium-size fires (2 thousand hectares $<S<20$ thousand hectares); (3) small-size fires $(S<2$ thousand hectares). Various scenarios are known for wildfire spreading in the boreal forests of Siberia $[31,32,34,44]$. The spread of small- and medium-size fire is possible in selected taxa of vegetation, bypassing waterlogged ones, while the large-scale or "landscape fires" spreads over whole types of vegetation of landscape. This category of fire is characterized by long activity, large area burned, and significant variability of intensity. Siberian fires of this category are prevalent mainly in larch close stands, accounting for up to $75-90 \%$ of the total area of annual area burned $[4,10,28]$. Our findings quantify the proportion of stand-replacement fires (in terms of dNBR range) from $7-12 \%$ for the category of small-size fire to $15-20 \%$ for large-scale fire. At the same time, medium-size fire ( 2 thousand hectares $<S<20$ thousand hectares) was accompanied by the highest degree of fire damage in $25-35 \%$ of the total area burned.

Finally, we applied results to classify the total area of forest burnt in 2021. From the total area of fires, which was 10 million hectares (https:/ / public.aviales.ru/main_pages/public. shtml/, accessed on 1 December 2021) [7], we calculated the area of the "healthy/unburned vegetation" class (5-7\% of total), as well as the area of "stand-replacement fires" (at least $12-33 \%$ of total), taking into account the types of forest stands. Hence, the total area of the "healthy/unburned vegetation" class was at least 700 thousand hectares, and the area of "stand-replacement fires" was 2500 thousand hectares in 2021 in eastern Siberia. Further investigation of fire severity for 2002-2020 will be useful for evaluating stand-replacement fire dynamics during the last two decades of climate change $[3,4,6,33]$ in Siberia. Detailed analysis for long-term wildfires databank makes it possible to implement our findings into a fire monitoring system in Russia, both at regional and federal levels.

\section{Conclusions}

The degree of fire impact varies significantly depending on the density of forest stands, the dominant tree species, and the category of fire by areas burned. The proportion of severe fires varied according to the transition from dominant larch stands $(33.2 \%$ of the area burned) to pine (12.6\%) and dark coniferous (up to $26.4 \%$ ) on average. To refined estimates of fire impact, it is necessary to link fire scars to vegetation maps and to take into account the types of forest stands and the density of tree stands. The current proportion of stand-replacement fires in eastern Siberia is $12-33 \%$ depending on vegetation type and tree density, which is about 2500 thousand hectares in 2021 in the region. Additionally, the "healthy/unburned vegetation" class was quantified at least 700 thousand hectares in 2021. However, climate change will provoke the spread of fires in the zone of northern Siberia, increase the area burned, and the proportion of severe fire, as well as increase the share of fires of all categories in larch stands of boreal forests. An increase in stand-replacement fires in the future should be expected in the boreal forests of eastern Siberia.

Author Contributions: Conceptualization, E.P.; methodology, E.P.; software, A.Z. and E.P.; validation, E.P., T.P. and A.Z.; resources, E.P.; data curation, E.P.; writing-original draft preparation, E.P. and T.P.; writing-review and editing, E.P.; visualization, E.P. and A.Z.; supervision, E.P.; funding acquisition, T.P. All authors have read and agreed to the published version of the manuscript.

Funding: This study was performed using the subject of project no. 0287-2021-0008 (IF SB RAS) and no. 0287-2021-0040 (KSC SB RAS). This research was partly funded by the Russian Foundation for Basic Research (RFBR) and the Government of the Krasnoyarsk Krai and Krasnoyarsk Krai Foundation for Research and Development Support, no. 20-44-242002. The study was supported by the Tomsk State University Development Programme («Priority-2030»).

Institutional Review Board Statement: Not applicable.

Informed Consent Statement: Not applicable. 
Data Availability Statement: Publicly available datasets were analyzed in this study. These data can be found here: http:/ / pro-vega.ru/maps/ (accessed on 1 December 2021) and https: / / worldview. earthdata.nasa.gov/ (accessed on 1 December 2021).

Acknowledgments: The satellite data-receiving equipment used was provided by the Center of Collective Usage of Federal Research Center "Krasnoyarsk Science Center, Siberian Branch of Russian Academy of Sciences", Krasnoyarsk, Russia. Since 2017, we have been monitoring fires as an activity of The Regional Eurasian Fire Monitoring Center (Krasnoyarsk, Russia) under an agreement between V.N. Sukachev Institute of Forest (Krasnoyarsk, Russia) and The Global Fire Monitoring Center (GFMC, Germany, https://gfmc.online/).

Conflicts of Interest: The authors declare no conflict of interest.

\section{References}

1. Shvidenko, A.Z.; Nilsson, S. Extent, Distribution, and Ecological Role of Fire in Russian Forests. In Fire, Climate Change, and Carbon Cycling in the Boreal Forest; Ecological Studies (Analysis and Synthesis); Kasischke, E.S., Stocks, B.J., Eds.; Springer: New York, NY, USA, 2000; Volume 138. [CrossRef]

2. Flannigan, M.; Stocks, B.; Turetsky, M.; Wotton, M. Impacts of climate change on fire activity and fire management in the circumboreal forest. Glob. Chang. Biol. 2009, 15, 549-560. [CrossRef]

3. McCarty, J.L.; Aalto, J.; Paunu, V.-V.; Arnold, S.R.; Eckhardt, S.; Klimont, Z.; Fain, J.J.; Evangeliou, N.; Venäläinen, A.; Tchebakova, N.M.; et al. Reviews and syntheses: Arctic fire regimes and emissions in the 21st century. Biogeosciences 2021, 18, 5053-5083. [CrossRef]

4. Kharuk, V.I.; Ponomarev, E.I.; Ivanova, G.A.; Dvinskaya, M.L.; Coogan, S.C.P.; Flannigan, M.D. Wildfires in the Siberian taiga. Ambio 2021, 50, 1953-1974. [CrossRef] [PubMed]

5. Hayasaka, H. Rare and Extreme Wildland Fire in Sakha in 2021. Atmosphere 2021, 12, 1572. [CrossRef]

6. Zhang, Z.; Wang, L.; Xue, N.; Du, Z. Spatiotemporal Analysis of Active Fires in the Arctic Region during 2001-2019 and a Fire Risk Assessment Model. Fire 2021, 4, 57. [CrossRef]

7. Remote Monitoring Information System of the Federal Forestry Agency. Space Monitoring Data Report. 2021. Available online: https:/ / public.aviales.ru/main_pages/public.shtml (accessed on 1 December 2021). (In Russian).

8. Bartalev, S.; Egorov, V.; Zharko, V.; Loupian, E.; Plotnikov, D.; Khvostikov, S.; Shabanov, N. Land Cover Mapping over Russia Using Earth Observation Data; Russian Academy of Sciences' Space Research Institute: Moscow, Russian, 2016; 208p.

9. Bartalev, S.A.; Stytsenko, F.V. An Assessment of the Forest Stands Destruction be Fires Based on the Remote Sensing Data on a Seasonal Distribution of Burnt Areas. Russ. J. For. Sci. 2021, 2, 115-122. [CrossRef]

10. Ponomarev, E.I.; Yakimov, N.D.; Ponomareva, T.V.; Yakubailik, O.E.; Conard, S.G. Current Trend of Carbon Emissions from Wildfires in Siberia. Atmosphere 2021, 12, 559. [CrossRef]

11. Ponomarev, E.I.; Masyagina, O.V.; Litvintsev, K.Y.; Ponomareva, T.V.; Shvetsov, E.G.; Finnikov, K.A. The effect of post-fire disturbances on a seasonally thawed layer in the permafrost larch forests of Central Siberia. Forests 2020, 11, 790. [CrossRef]

12. Ponomareva, T.V.; Litvintsev, K.Y.; Finnikov, K.A.; Yakimov, N.D.; Sentyabov, A.V.; Ponomarev, E.I. Soil Temperature in Disturbed Ecosystems of Central Siberia: Remote Sensing Data and Numerical Simulation. Forests 2021, 12, 994. [CrossRef]

13. Kirdyanov, A.V.; Saurer, M.; Siegwolf, R.; Knorre, A.A.; Prokushkin, A.S.; Churakova, O.V.; Fonti, M.V.; Büntgen, U. Long-term ecological consequences of forest fires in the continuous permafrost zone of Siberia. Environ. Res. Lett. 2020, 15, 034061. [CrossRef]

14. dos Santos, S.M.B.; Bento-Gonçalves, A.; Franca-Rocha, W.; Baptista, G. Assessment of Burned Forest Area Severity and Postfire Regrowth in Chapada Diamantina National Park (Bahia, Brazil) Using dNBR and RdNBR Spectral Indices. Geosciences 2020, 10, 106. [CrossRef]

15. Bartalev, S.A.; Egorov, V.A.; Krylov, A.M.; Stytsenko, F.V.; Khovratovich, T.C. The evaluation of possibilities to assess forest burnt severity using multi-spectral satellite data. Mod. Probl. Remote Sens. Earth Space 2010, 3, 215-225. (In Russian)

16. Krylov, A.; McCarty, J.L.; Potapov, P.; Loboda, T.; Tyukavina, A.; Turubanova, S.; Hansen, M.C. Remote sensing estimates of stand-replacement fires in Russia, 2002-2011. Environ. Res. Lett. 2014, 9, 1-8. [CrossRef]

17. Delcourt, C.J.F.; Combee, A.; Izbicki, B.; Mack, M.C.; Maximov, T.; Petrov, R.; Rogers, B.M.; Scholten, R.C.; Shestakova, T.A.; van Wees, D.; et al. Evaluating the Differenced Normalized Burn Ratio for Assessing Fire Severity Using Sentinel-2 Imagery in Northeast Siberian Larch Forests. Remote Sens. 2021, 13, 2311. [CrossRef]

18. Rouse, J.W., Jr.; Haas, R.H.; Schell, J.A.; Deering, D.W. Monitoring the Vernal Advancement and Retrogradation (Green Wave Effect) of Natural Vegetation. Progress Reports RSC 1978-1 93. Texas A \& M University, 1973. Available online: https://ntrs.nasa. gov/citations/19730009608 (accessed on 1 December 2021).

19. Tucker, C.J. Red and Photographic Infrared Linear Combinations Monitoring Vegetation. J. Remote Sens. Environ. 1979, 8, 127-150. [CrossRef]

20. Ponomarev, E.I.; Ponomareva, T.V. Method for Revealing Stage of Vegetation Cover Restoration by Analyzing Temperature Anomalies on Satellite Imagery of Underlying Surface in Thermal (IR) Range of Spectrum. Invention patent No RU 2754968, 2021; Priority reference No2021103603 from 15 February 2021. Available online: https:/ / www.fips.ru/ofpstorage/BULLETIN/IZPM/ 2021/09/10/INDEX_RU.HTM (accessed on 1 December 2021). (In Russian). 
21. Key, C.H.; Benson, N.C. Landscape Assessment: Sampling and Analysis Methods. In FIREMON: Fire Effects Monitoring and Inventory System. Available online: https:/ / www.fs.usda.gov/treesearch/pubs/24066 (accessed on 1 December 2021).

22. French, N.H.F.; Kasischke, E.S.; Halle, R.J.; Murphy, K.A.; Verbyla, D.L.; Hoy, E.E.; Allen, J.L. Using Landsat data to assess fire and burn severity in the North American boreal forest region: An overview and summary of results. Int. J. Wildland Fire 2008, 17, 443-462. [CrossRef]

23. Chu, T.; Guo, X.; Takeda, K. Temporal dependence of burn severity assessment in Siberian larch (larix sibirica) forest of northern Mongolia using remotely sensed data. Int. J. Wildland Fire 2016, 25, 685-698. [CrossRef]

24. Guindon, L.; Gauthier, S.; Manka, F.; Parisien, M.-A.; Whitman, E.; Bernier, P.; Beaudoin, A.; Villemaire, P.; Skakun, R. Trends in wildfire burn severity across Canada, 1985 to 2015. Can. J. For. Res. 2021, 5, 1230-1244. [CrossRef]

25. Stytsenko, F.V. Development and application of methods and automated technology for assessing pyrogenic forest death based on satellite data. In Abstract of Dissertation, Candidate of Technical Sciences: 25.00.34; IKI: Moscow, Russia, 2016; 24p. (In Russian)

26. Fan, R.; Hou, B.; Liu, J.; Yang, J.; Hong, Z. Registration of Multiresolution Remote Sensing Images Based on L2-Siamese Model. IEEE J. Sel. Top. Appl. Earth Obs. Remote Sens. 2021, 14, 237. [CrossRef]

27. Wang, P.; Wang, L.; Leung, H.; Zhang, G. Super-Resolution Mapping Based on Spatial-Spectral Correlation for Spectral Imagery. IEEE Trans. Geosci. Remote Sens. 2021, 59, 2256-2268. [CrossRef]

28. Ponomarev, E.I.; Shvetsov, E.G. Satellite detection of forest fires and geoinformation methods for calibration of results. Explor Earth Space 2015, 1, 84-91. [CrossRef]

29. Bartalev, S.A.; Ershov, D.V.; Isaev, A.S.; Potapov, P.V.; Turubanova, S.A.; Yaroshenko, A.Y. Russia's Forests Dominating Forest Types and Their Canopy Density Scale 1: 14000 000; Moscow, Russia, 2004. Available online: https://www.researchgate.net/publication/ 272680068_Russia \T1 \textquoterights_Forests_Dominating_Forest_Types_and_Their_Canopy_Density (accessed on 1 December 2021).

30. Shvetsov, E.G.; Ponomarev, E.I. Postfire Effects in Siberian Larch Stands on Multispectral Satellite Data. Contemp. Probl. Ecol. 2020, 1, 104-112. [CrossRef]

31. McRae, D.J.; Conard, S.G.; Ivanova, G.A.; Sukhinin, A.I.; Baker, S.; Samsonov, Y.N.; Blake, T.W.; Ivanov, V.A.; Ivanov, A.V.; Churkina, T.V.; et al. Variability of fire behavior, fire effects, and emissions in Scotch pine forests of Central Siberia. Mitig. Adapt. Strateg. Glob. Chang. 2006, 11, 45-74. [CrossRef]

32. Ivanova, G.A.; Conard, S.G.; McRae, D.J.; Bezkorovaynaya, I.N.; Bogorodskaya, A.V.; Zhila, S.V.; Ivanov, V.A.; Ivanov, A.V.; Kovaleva, N.M.; Krasnoshchekova, E.N.; et al. The Impact of Fires on the Ecosystem Components of the Middle Taiga Pine Forests of Siberia; Science: Novosibirsk, Russia, 2014; 232p, ISBN 978-5-02-019163-1. (In Russian)

33. IPCC. Summaries, Frequently Asked Questions, and Cross-Chapter Boxes, Report of the Intergovernmental Panel on Climate Change. In Climate Change 2014: Impacts, Adaptation, and Vulnerability; Field, C.B., Barros, V.R., Dokken, D.J., Mach, K.J., Mastrandrea, M.D., Bilir, T.E., et al., Eds.; World Meteorological Organization: Geneva, Switzerland, 2014.

34. Valendik, E.N.; Kisilyakhov, E.K.; Ryzhkova, V.A.; Ponomarev, E.I.; Danilova, I.V. Conflagration Fires in Taiga Landscapes of Central Siberia. Geogr. Nat. Resour. 2014, 35, 41-47. [CrossRef]

35. Conard, S.G.; Ponomarev, E.I. Fire in the North-The 2020 Siberian Fire Season. Wildfire 2020, $29,26-32$.

36. Goldammer, J.G.; Sukhinin, A.; Csiszar, I. The Current Fire Situation in the Russian Federation: Implications for Enhancing International and Regional Cooperation in the UN Framework and the Global Programs on Fire Monitoring and Assessment. In Proceedings of the GFMC Contribution to the International Workshop “New Approaches to Forest Protection and Fire Management at an Ecosystem Level" Khabarovsk, Russian, 9-12 September 2003; 33p.

37. de Groot, W.J.; Cantin, A.S.; Flannigan, M.D.; Soja, A.J.; Gowman, L.M.; Newbery, A. A comparison of Canadian and Russian boreal forest fire regimes. For. Ecol. Manag. 2013, 294, 23-34. [CrossRef]

38. Furyaev, V.V. Pyrological regimes and dynamics of the southern taiga forests in Siberia. In Fire in Ecosystems of Boreal EURASIA; Goldammer, J.G., Furyaev, V.V., Eds.; Kluwer Academic Publishers: Dordrecht, The Netherlands, 1996; pp. 168-185.

39. Korovin, G.N. Analysis of the Distribution of Forest Fires in Russia. In Fire in Ecosystems of Boreal Eurasia; Forestry Sciences; Goldammer, J.G., Furyaev, V.V., Eds.; Springer: Dordrecht, The Netherlands, 1996; Volume 48, pp. 112-128. [CrossRef]

40. Conard, S.G.; Davidenko, E.P. Fire in Siberian Boreal Forests-Implications for Global Climate and Air Quality. In Proceedings of the International Symposium on Air Pollution and Climate Change Effects on Forest Ecosystems. Gen. Tech. Rep. PSW-GTR-166; USDA Forest Service: Albany, CA, USA, 1998; pp. 87-94.

41. Kajii, Y.; Kato, S.; Streets, D.; Nancy, Y.T.; Shvidenko, A.; Nilsson, S.; McCallum, I.; Minko, N.; Abushenko, N.A.; Altyntsev, D.; et al. Boreal forest fires in Siberia in 1998: Estimation of area burned and emissions of pollutants by advanced very high resolution radiometer satellite data. J. Geophys. Res. 2002, 107, ACH 4-1-ACH 4-8. [CrossRef]

42. Matveeva, T.M.; Matveev, A.M. Wildfires in Mountain Forests of Middle and Southern Taiga; DarMa: Krasnoyarsk, Russia, 2008; 213p (In Russian)

43. Zalesov, S.V. Lesnaya Pirologiya (Forest Pyrology); Izdatelstvo UGLTU: Yekaterinburg, Russia, 2013; 332p. (In Russian)

44. Ivanova, G.A.; Kukavskaya, E.A.; Ivanov, V.A.; Conard, S.G.; McRae, D.J. Fuel characteristics, loads and consumption in Scots pine forests of central Siberia. J. For. Res. 2020, 31, 2507-2524. [CrossRef] 